\title{
Using Digital Visualization of Archival Sources to Enhance Archaeological Interpretation of the 'Life History' of Ships: The Case Study of HMCS/HMAS Protector
}

\author{
James Hunter, Emily Jateff, and Anton van den Hengel
}

\begin{abstract}
In 2013, researchers affiliated with the South Australian Maritime Museum and University of Adelaide's Australian Centre for Visual Technologies [ACVT] conducted an archaeological and laser scanning survey of the former Australian warship HMCS/HMAS Protector. Between its launch in 1884 and service in the First World War, Protector was substantially modified. Once decommissioned, the ship again underwent drastic changes. While several archival photographs exist that depict Protector at various stages of its life, they provide only scant understanding of the transformative processes applied to Protector's hull. Researchers at ACVT have developed methods of generating 3D models from archival photographs, and are using Protector as a case study. Models have been created that depict the vessel at three specific periods of its service life, which in turn has enabled archaeologists to identify gradual variations to Protector's hull that, in some cases, were so subtle they could not be discerned in existing archival photographs and other historic media.
\end{abstract}

\section{Keywords}

Australia $\cdot$ Heron Island $\cdot$ HMAS Protector $\cdot$ Life history - Archival resources $\cdot$ Shipwrecks

J. Hunter $(\square) \cdot$ E. Jateff

Australian National Maritime Museum, Sydney, Australia

e-mail: james.hunter@anmm.gov.au; emily.jateff@anmm.gov.au

A. van den Hengel

University of Adelaide, Adelaide, Australia

e-mail: anton.vandenhengel@adelaide.edu.au

\subsection{Introduction}

During the latter half of 2013, a team of researchers affiliated with the South Australian Maritime Museum [SAMM] and University of Adelaide's Australian Centre for Visual Technologies [ACVT] conducted a comprehensive archaeological and laser scanning survey of the former Australian warship Protector (for additional information about this project, see Hunter and Jateff 2016; Hunter et al. 2016; MacLeod et al. 2014). Originally constructed as a gunboat and commissioned as a light cruiser for South Australia's colonial navy in 1884, Protector would later be integrated into the Commonwealth Naval Forces and Royal Australian Navy. It served in both the Yihetuan Movement (Boxer Rebellion) and First World War before being decommissioned from naval service in the 1920s. Subsequently converted into an unpowered lighter, the vessel operated in the waters of Port Phillip Bay, Victoria before being recalled for a brief period of military service during the Second World War. Damaged while en route to participate in the American assault on Papua New Guinea, Protector was condemned, sold, and towed to Heron Island on Australia's Great Barrier Reef in 1944, where it was installed as a breakwater.

Although exposed to the ravages of time and tide for over 70 years, Protector's hull has remained largely intact and is still a prominent aspect of Heron Island's seascape (Fig. 6.1). The midships structure, however, has experienced accelerated deterioration and collapse during the past three decades, and corrosion and the elements both continue to exact a toll on the vessel's surviving fabric. The effort to archaeologically document Protector was partly borne of the realization that it had not been previously surveyed and its surviving hull was progressively more compromised and in danger of complete structural collapse. In addition, four significant anniversaries in the vessel's history—its launch and delivery to South Australia (1884), involvement in Australia's capture of New Guinea during the First World War (1914), decommissioning from Royal Australian Navy service (1924), and 


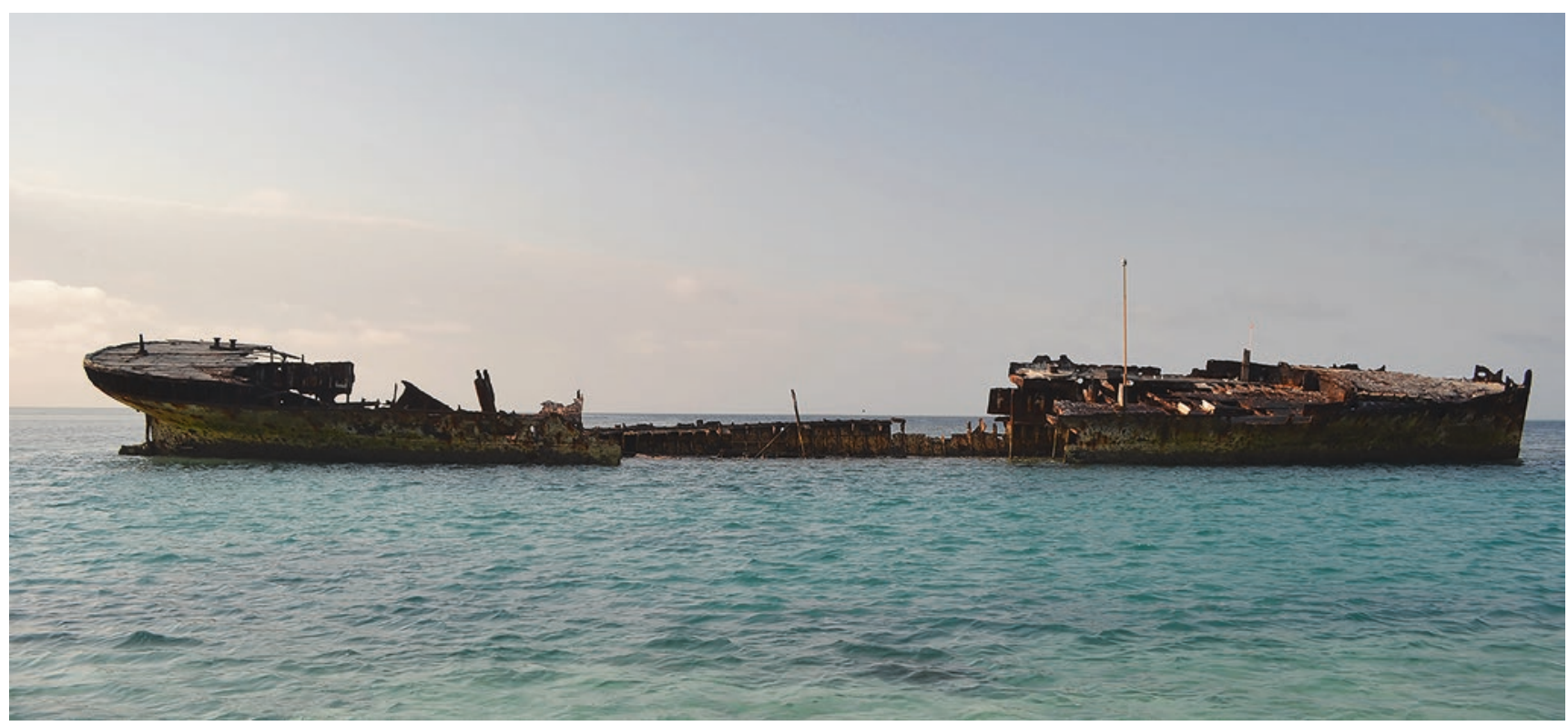

Fig. 6.1 Protector's surviving hull, as it appeared in 2013 at the time of the archaeological and laser scanning survey (J. Hunter)

installation as a breakwater at Heron Island (1944) —would occur in 2014, and SAMM planned to develop an exhibition to coincide with and commemorate these dates.

Central to the exhibition was a desire to digitally capture Protector and exhibit it virtually to a South Australian audience. Faced with this challenge, SAMM sought the advice and expertise of ACVT, and a resulting collaborative research initiative secured project funding from the Australian Research Council's Linkage Grant Program. The primary project goals were to laser scan Protector's hull where exposed above the waterline and develop the means to produce 3D digital models of the vessel from archival images. Protector was relatively well-photographed over the course of its military and civilian careers, and the resulting image archive proved ideal for the project. Consequently, it was chosen by ACVT as the pilot study in a potentially groundbreaking initiative to digitally model historic photographs. Models of Protector rendered from archival images have revealed subtle changes to its hull, superstructure, armament and fittings over time, which in turn have informed the overall interpretation of its evolution as a military and civilian watercraft.

\subsection{Iconography and Maritime Archaeology}

The use of iconographic images-including historic photographs-as an interpretive dataset in maritime archaeology has existed for nearly as long as the discipline itself. Indeed, prior to the advent of maritime archaeology as an area of formal study, iconographic investigations were often the only means by which ancient watercraft were analysed and interpreted, and served to "initiate the whole of what eventually became known as "maritime archaeology" (Flatman 2004, 1276, 2014, 4668). Following the emergence of shipwreckfocussed archaeological investigations in the 1960s, the use of iconography as a source for ancient and historic ship studies declined, as did its prominence as an area of academic inquiry. Its existence never ceased entirely, however, and maritime iconography continued to inform archaeological studies-particularly those with a ship reconstruction focus (see Crumlin-Pedersen 2000; McGrail 1998; Steffy 1994; Villain-Gandossi 1979). The use of iconography in maritime archaeology persists to this day, has expanded to cover broader thematic topics such as maritime cultural landscapes (see Flatman 2004), and continues to benefit from a variety of image types, including paintings, sketches, ship plans and schematics. Historic photographs have increasingly become a more common dataset in maritime archaeology as the discipline's scope has expanded to encompass ships and shipwrecks from the late-nineteenth and early-to-mid twentieth centuries.

Maritime archaeologists have made qualitative statements about historic vessels through quantitative analysis of iconographic data. For example, Winter and Burningham (2001) employed the use of multiple iconographic images to identify and differentiate variants of early seventeenth-century Dutch watercraft. The authors originally intended to utilize contemporary Dutch maritime art to develop a reconstruction of Duyfken, a small jacht for which no existing ship plans are known to exist (Winter and Burningham 2001, 57). Univariate and multivariate morphometric statistical analyses of marine paintings, engravings and pen-and-ink drawings revealed the 
existence of four distinct classifications of three-masted, square-rigged Dutch sailing vessels during the early seventeenth century. These vessel types—ships, jachts, large jachts and small jachts - were not previously identified in historical or archaeological literature, opening up new potential research avenues in Dutch ship design. In terms of utility, the authors contend morphometric analysis of iconographic data provided 'objective confirmation of the validity of the design of the Duyfken reconstruction... and should be seen as a necessary part of all ship design reconstruction' (Winter and Burningham 2001, 72-73).

Although there are no published studies in which 3D models of archival iconography have been specifically created and used as an interpretive tool in maritime archaeology, there have been efforts to integrate historical imagery with existing 3D models of heritage sites. A team led by Mathieu Aubry (see Aubry 2015; Aubry et al. 2013) has recently developed an algorithm that reliably aligns 3D models of historic structures with corresponding 'arbitrary' 2D depictions, including 'drawings, paintings and historical photographs.' The algorithm builds upon prior research in computer vision that aligns images using 'local features', 'contours' and 'discriminative learning' to search for 'discriminative visual elements' within rendered 3D models of a given structure (Aubry et al. 2013, 1-3; for discussions of prior research in this area, see Baatz et al. 2012; Baboud et al. 2011; Dalal and Triggs 2005; Doersch et al. 2012; Felzenszwalb et al. 2010; Hartley and Zisserman 2004; Huttenlocher and Ullman 1987; Lowe 1987, 2004; Rapp 2008; Russell et al. 2011; Shrivastava et al. 2011; Sivic and Zisserman 2003; Snavely et al. 2006). Using a technique similar to object detection, it then matches these visual elements with matching elements in 2D images. The application is able to make these alignments "despite large variations in rendering style (e.g. watercolor, sketch, historical photograph)... and structural changes [within] the scene' (Aubry et al. 2013, 1). Significantly, it also produced better results than a variety of baseline methods, including human detection.

While ground-breaking, Aubry's technique relies upon 3D models of existing objects/structures of interest, and it is therefore of limited or no use in instances where a 3D model cannot be generated because the structure has either changed significantly or is no longer present. This is particularly true of most shipwreck and vessel abandonment sites. Surviving hull structure is often limited to the area beneath the waterline, which is rarely-if ever-documented in iconographic sources. In addition, surviving elements of wrecked and abandoned vessels above the waterline are usually so fundamentally altered by natural and cultural transformative processes that they offer few 'discriminative visual elements' with which to compare them to archival imagery. One way to combat this problem is to generate $3 \mathrm{D}$ models of vessels as they originally appeared, and then use these models in turn to search for variations in their hull, superstructure, armament and fittings over time.

\subsection{A Means for Interpretation: 3D Modelling of Archival Images}

Producing 3D models from photographs is one of the fundamental challenges of image analysis, and has long been studied within the field of computer vision. Although a range of methods have been devised (see Szeliski 2010 for a compilation of available techniques), the primary example applicable to archival photographs is what is known as the 'Structure-from-Motion' (SfM) approach (see Hartley and Zisserman 2004 for technical details). SfM is based on a simplified model of image formation, which reflects the geometry of an idealized pin-hole camera. The fundamental challenge with interpreting images from a pin-hole camera, or indeed any traditional camera, is that an infinite number of scenes may give rise to any particular image. This is because cameras effectively remove depth information from a captured scene, and produce images that are flat, 2D representations (see Hartley and Zisserman 2004 for technical details). The images they create do not record the depths or sizes of individual objects within the scene, or the elements they are made up of. In theory, it would not be possible to differentiate between a close-up image of a toy car, and an image of an identical, but larger (i.e., real) car that is further away. Humans overcome this problem using prior knowledge of the size of general objects, but this is knowledge that the SfM method does not possess.

One means for resolving the problem is the use of image pairs instead of single images. The SfM approach exploits a mathematical model of the mechanism by which multiple images of the same scene are created. It takes into account that light travels in a straight line, and explains the manner in which the relative positions of objects in an image change as the camera's position changes. The model has a set of parameters that must be adjusted to match a particular scene and the camera(s) that took the image(s). Key to generating an accurate 3D reconstruction of a scene captured by a simplified camera is to find SfM parameters that best reflect the original scene, and the position(s) and internal characteristics of the camera(s) used.

Unfortunately, archival photographs were not typically taken with 3D modelling in mind, and the cameras that captured the images are long gone. Consequently, in the vast majority of cases it is impossible to take a suitable set of scene measurements to analyse camera positions, or inspect the camera geometry, so as to guide the SfM process. All that is available are the images themselves. An interesting aspect of the projective geometry that underpins $\mathrm{SfM}$ is that, by making a suitable set of assumptions or adding external information, it is often possible to estimate the missing parameters. Assumptions such as the water or ground in an image being horizontal, walls being vertical, and objects being symmetric can be used to imply constraints in the optimization problem that SfM solves. By optimising the param- 
eters of the SfM model so that it best reflects these assumptions, in addition to the image-based measurements, a mathematical model of the image-creation process may be recovered. Armed with such a model, it is possible to extract components of the model that identify the 3D characteristics of various objects within the scene.

One significant drawback to the SfM approach is that it only delivers a set of 3D position estimates for various points within the image. This set of position estimates is referred to as a point cloud, and represents a relatively poor model of $3 \mathrm{D}$ shape. Point clouds cannot be replicated with a 3D printer, nor rendered as anything but a set of dots. Consequently, a major avenue of inquiry in computer vision is the development of methods for converting point clouds into polygonal models such as may be used to 3D print facsimile objects. Offshoots of this research include visualization of archival imagery in augmented reality systems, and analysis of subtle design changes to historic structures over time. Critical to the successful achievement of these and other goals is the development of a means for converting point clouds into a set of polygons, or a 'polygonal mesh', that accurately reflects the original surface(s) of object(s) depicted in an historic image.

At a minimum, a set of polygons can be constructed that span the points within the point cloud. This method generates a surface, but not one that accurately reflects the surface of the actual object. Other methods already exist in which better polygonal meshes may be generated from a point cloud and set of images, and new techniques are currently in development. All, however, optimize a given polygonal mesh's parameters so that it best reflects the set of measurements derived from an archival image. VideoTrace, a software program used to generate realistic 3D models of objects from digital video, embodies one such approach and was used by ACVT to develop digital models of Protector from archival imagery (Fig. 6.2).

The VideoTrace 3D modelling process proceeds as follows: The user takes a video, and loads it into the software, which then carries out a standard structure-from-motion analysis of it. The result of this process is a spare 3D point cloud, and an estimate of the internal parameters and position of the camera for each frame of the video. What distinguishes VideoTrace from other image-based methods for generating low polygon count 3D models is the nature of the interaction, and the level of control that this gives the user over the final polygonal 3D model. VideoTrace uses the results of the structure-from-motion process to inform the interpretation of user interactions, which allows the user to focus on adding high-level, often semantic, information. This is particularly critical for archaeological applications, as it allows the user to exploit their expert knowledge to compensate for the fact that the data required to drive more traditional image-based modelling is unavailable.

\subsection{The Challenge of Digitally Modelling Archival Imagery}

The process outlined above applies a mathematical SfM model to a set of measurements acquired from available images. The model's parameters are then adjusted until they accurately align with each image's measurements - with the ultimate goal that the resulting model will reveal the original conditions under which the image was formed. A major drawback to SfM is that it relies on a set of assumptions, foremost of which is that all of the available images depict an identical historic scene. In reality, however, the scarcity of historical images of an object of interest make it unlikely that two images of the same object will have been taken at the same location, let alone the same time. SfM modelling attempts to reconstruct the image formation process by analysing differences between two images of the same scene. It does so by performing a mathematical analysis of the dependency between the position of a given object in an image, and the position(s) of the camera(s) that captured it. By analysing the differences between two images taken from different locations, it is possible to extrapolate the relative position(s) of the camera(s), and the relative positions of the depicted objects. This is the same mechanism by which humans see in 3D. Subtle differences in images that we see are caused by the relative positions of our eyes in our head. An analysis of those differences allows our brain to develop an estimate of the 3D shape of the scene we see. Significantly, this approach assumes the only differences in appearance between two images are caused by the respective locations of the cameras (or eyes).

Very few examples exist of multiple images taken of the same scene at exactly the same moment. Early stereoscopy represents one notable exception, and is a valuable data source. Unfortunately, stereoscopic images of historic objects, locations, or events are rare; consequently, those wishing to develop 3D models from archival photographs are faced with doing so from a body of imagery that is largely unsuitable for the purpose. Many historical images may share one or more objects or scenes, but because photography was once far less common than it is today, the total number of available photographs within a data set is typically small. This has a follow-on effect on the overall number of images featuring objects or scenes that were captured on film at the same time. The ability to confirm that two or more archival photographs were generated simultaneously is critical, as it is the best way to guarantee the objects and scenes they depict are no different from one another. Most historical images, even those that feature scenes that appear identical, were often produced at different times. 


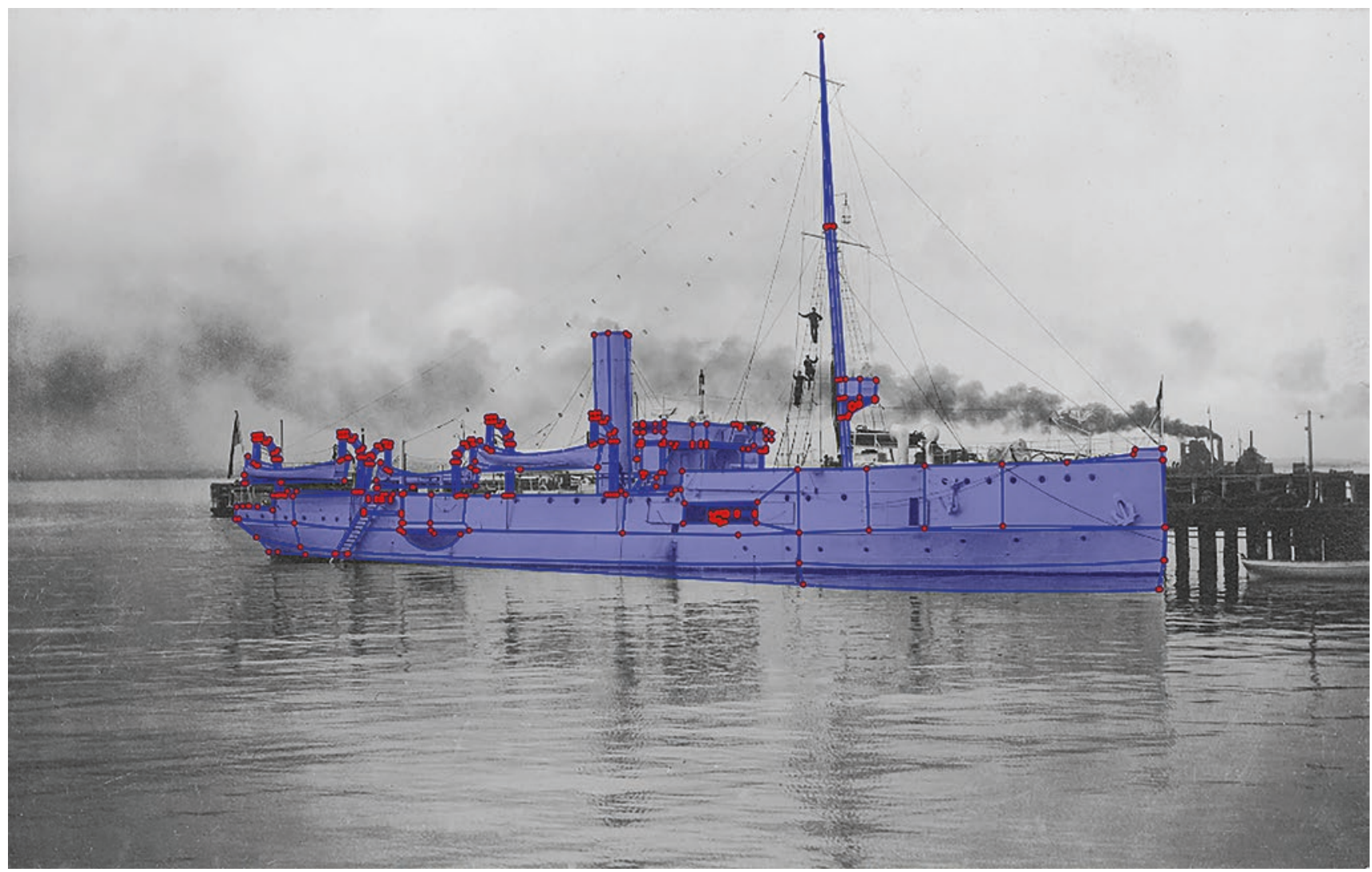

Fig. 6.2 Screen capture of a polygonal mesh superimposed over an archival photograph of HMAS Protector using the VideoTrace software program. (Image: ACVT; base image: South Australian Maritime Museum [John Bird Collection])

Consequently, the objects and scenes within them may appear unchanged, but often exhibit subtle variations.

Another challenge to developing 3D models of archival photographs is that the content that is actually common to all of the images in the set (typically the object of interest) makes up only a small part of the image. In the case of Protector, the image archive-while relatively large-depicts the vessel from different points of view in a variety of locations and configurations. A particular problem from a SfM standpoint is that Protector is the only common element among the majority of photographs, but comprises a relatively small percentage of each image. In addition, the shape of the ship changes quite dramatically between photographs, to the extent that certain features (such as armament or elements of superstructure) cannot be assumed to have remained in the same position, or even extant, from image to image. As mentioned, the ability to analyse variations in the appearance of common content between two images is the core component of the SfM approach. In instances where common content comprises a small percentage of images within a data set, instability is created within the mathematical model, which in turn can generate significant error in the estimates it generates.

\subsection{A Partial Solution}

Many of the problems described above can be counteracted by incorporating more photographs into the data set. However, this only helps if the additional images provide new views of the object. Because early photographs were difficult to produce and develop, great care was often taken to capture a scene from the best viewpoint, or depict an object from a 'canonical', or preferred position. As a consequence, many historic photographs effectively show the same point of view, and don't add new information to a given SfM dataset.

These problems affected efforts to model Protector's photo archive, but were corrected in part by the creation of 'pseudo images' from the vessel's construction plans (Fig. 6.3). In order for the SfM model to identify features in common with the archival photographs, the plans had to be manually processed. All photographic images are an accurate reflection of reality and consequently were processed using a standard, automatic SfM pipeline. By contrast, the handdrawn nature of the construction plans meant they were a reflection of the real (photographic) images, and as a result the SfM approach was inapplicable. Ultimately, the identification of correspondences between pseudo (hand-drawn) 


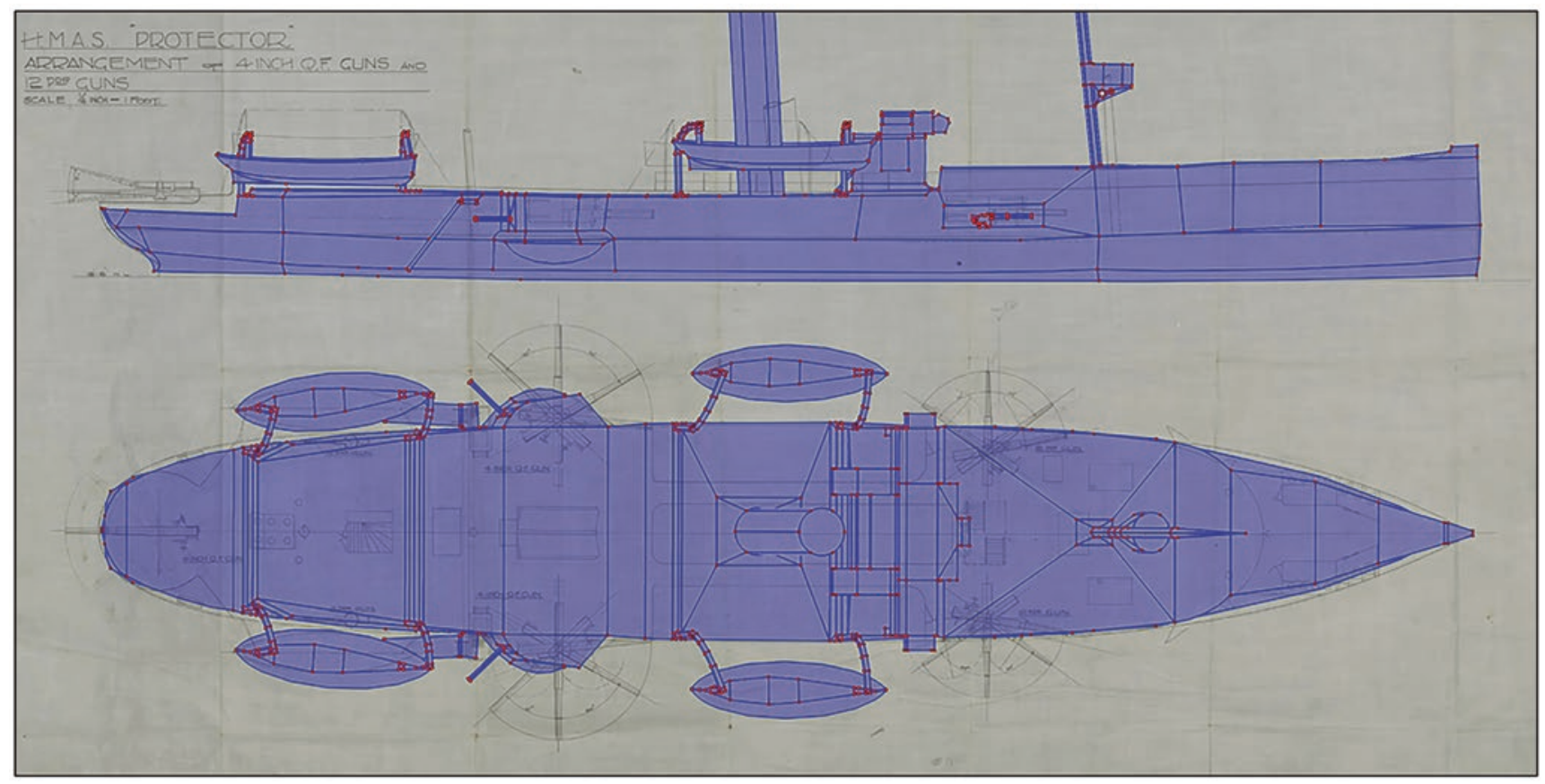

Fig. 6.3 Example of a 'pseudo image' developed from a 1922 plan of Protector's armament arrangement (ACVT; base image: National Archives of Australia [MP551/1:92/14])

images and real (photographic) images had to be carried out manually. These correspondences were significantly outnumbered by correspondences generated automatically between photographic images. While this proved somewhat of a drawback, creation of pseudo images generated alternate views of Protector from vastly different perspectives, which in turn contributed valuable geometric information that could be incorporated into the overall models. ACVT staff also consulted with project archaeologists to identify consistent hull and superstructure features within Protector's image archive.

\subsection{A Better Solution}

Despite the problems outlined above, human beings have very little trouble interpreting historical images. Human interpretation is less accurate than what is required for SfM modelling, but is far more flexible in its approach and applicability. While not necessarily able to generate a model suitable for 3D printing, the human process of image interpretation can be applied to a single photograph, derive information from previously unseen images, and is resistant to various forms of image degradation and deformation. The human mind is able to achieve this feat due to cumulative experience of real-world scenes and objects. This is accomplished through a lifetime of observing the world and interacting with it, which endows humans with the ability to easily recall and exploit their brain's 'information archive' when interpreting an image.
A current issue in SfM is how to incorporate the human mind's mechanism for reading historic photographs into the computing process of image interpretation. ACVT is currently conducting research in this area, and has made gains in generating 3D models from individual archival images (see $\mathrm{Li}$ et al. 2015). The neural network-based methods, however, that ACVT has developed require vast volumes of data for testing and manipulation, and these data sets tend to comprise extremely large format images and corresponding sets of laser scans. These data are often difficult to acquire, and the image content they contain frequently limits the methodologies that may be employed during the modelling process. In many cases, the models generated from these data sets tend to be in the form of height maps rather than full 3D models - which makes them wholly inappropriate for many of the modelling tasks that are of interest to historians and archaeologists. ACVT's research to generalize this approach continues, as do its efforts to generate accurate, full 3D models of historical objects and scenes.

\subsection{Applying 3D Archival Imagery to Interpret Protector's 'Life History'}

Utilising available image assets, ACVT generated composite digital models that depicted Protector's external hull and superstructure during three general phases of its career (Fig. 6.4). The first showed the vessel in its 'as-built' configuration in 1884 (as a South Australian colonial gunboat), 


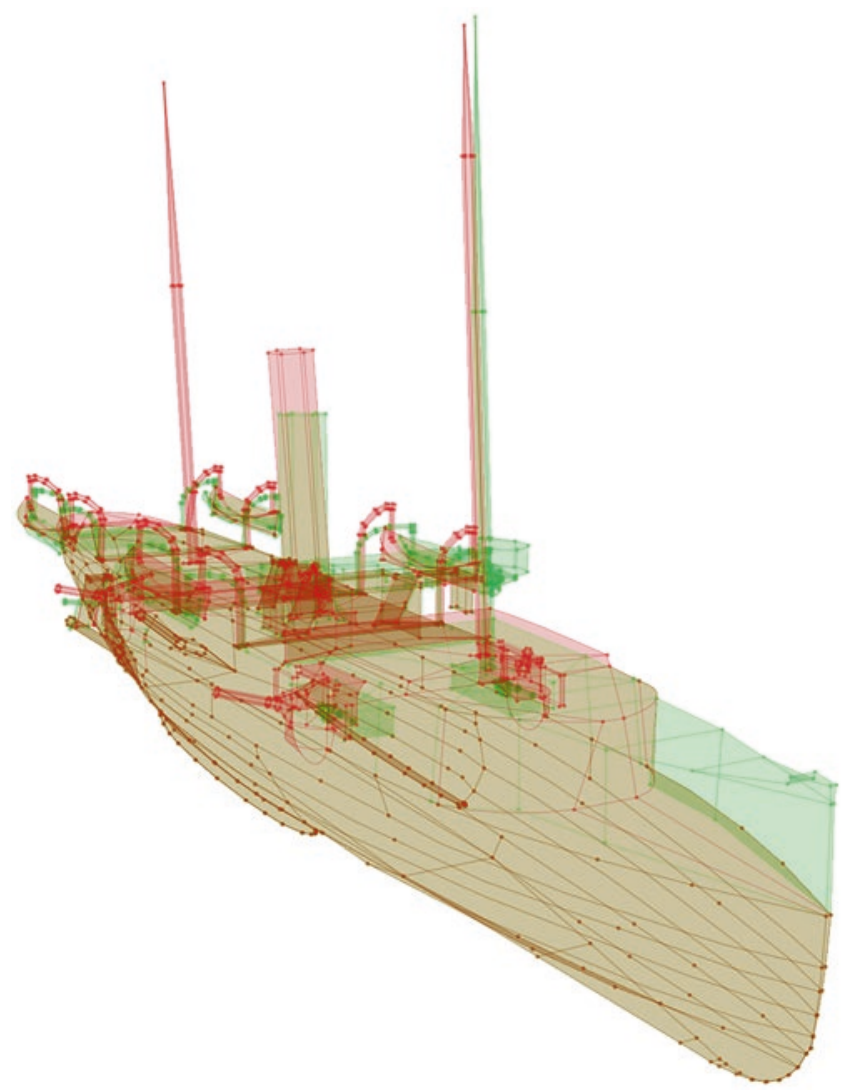

Fig. 6.4 Isometric view of superimposed digital models of Protector's external hull as it appeared in its colonial (red) and national (green) navy configurations. Brown indicates where both models overlap (ACVT/authors)

while the second and third highlighted its appearance as a Royal Australian Navy auxiliary warship (1911-1924) and civilian lighter (1924-1944), respectively. To fully understand and appreciate the transformative processes that were applied to Protector's hull over the course of its life as a functional watercraft-a period totalling 60 years-a brief discussion of its historical background is necessary.

Her Majesty's Colonial Ship (HMCS) Protector was originally purchased by the South Australian colonial government in 1882 in response to several 'Russian Scares' that plagued the Australian colonies during the 1860s, 1870s and 1880s (Jeisman 2012, 37-38; Nicholls 1988, 80-84). It was constructed according to a 'flat-iron' gunboat design first introduced during the Crimean War (1853-1856) and exhibited a unique silhouette that included a forward section with incredibly low freeboard, a prominent centrally positioned funnel, and armament that exceeded what was considered normal for a warship of its size (Gillett 1982, 62; Jeisman 2012, 44, 49-55; Jones 1986, 62-63). For the next 40 years, Protector was an active asset of the South Australian colonial navy, Commonwealth Naval Forces, and Royal Australian
Navy. It participated in two major conflicts: suppression of the Yihetuan Movement in China in 1900, and the First World War (1914-1918). Upon integration within the Royal Australian Navy in 1911, the vessel was renamed His Majesty's Australian Ship (HMAS) Protector and its armament altered. Its First World War service included acting as a tender to the Australian submarines $A E 1$ and $A E 2$, guarding the port of Rabaul in New Guinea, and serving as a patrol vessel in Australian coastal waters (Jeisman 2012, 289). During its final years of naval service, Protector was renamed HMAS Cerberus and operated as a tender at the Flinders Naval Depot in Victoria.

In 1924, Protector reverted to its original name and was decommissioned from the Royal Australian Navy. It was subsequently purchased by civilian interests and stripped of armament, engines and machinery, which were sold at auction. The remaining hulk was also sold, converted into a lighter, and in 1931 ended up in the possession of Melbournebased Victorian Lighterage Pty Ltd. Renamed Sidney, the vessel stored and transported bulk commodities, including fuel oil and wool, in Port Phillip Bay for several years (Gillett 1982, 68; Jeisman 2012, 291; Pennock 2001, 95). During the Second World War, Sidney was requisitioned by the US Army and served the Small Ships Section of the US Army Services of Supply under the vessel designation $S$-226. Loaded with various army stores, Sidney was in transit to New Guinea in September 1943 when it collided with another vessel at the Queensland port of Gladstone. Four months later, the US Army was preparing to strip and scuttle the vessel when Cristian Poulson, proprietor of a tourist resort at nearby Heron Island on the Great Barrier Reef, offered $£ 10$ for the hulk (Gillett 1982, 68; Jeisman 2012, 291; Pennock 2001, 95-96). In April 1944, Sidney was towed to the western side of Heron Island and installed as a breakwater.

Between integration into the Commonwealth Naval Forces in 1901 and the outbreak of the First World War in 1914, Protector's hull underwent a series of significant modifications. One of the most substantial alterations was to the vessel's bow, which in 1912 was built up to the level of existing superstructure amidships. This created additional working and living space, increased Protector's freeboard in the forward section by approximately 4 metres, and almost certainly improved the ship's overall seaworthiness. The stern bulwarks, by contrast, were lowered slightly during this period-possibly in preparation for the installation of minesweeping gear. A series of planned alterations to Protector include an early twentieth-century schematic detailing a proposed arrangement for minesweeping gear and associated equipment. These plans feature an annotation stating the stern bulwark would be 'cut away' to facilitate deployment of a water kite, used for minesweeping, and its towing array 
(National Archives of Australia [NAA], MP551/1, 92/20; United States Navy 1917, 5). Although the height of the stern bulwarks was reduced, and two sections were removed entirely, the minesweeping apparatus does not appear to have ever been installed.

While changes to Protector's bow and stern are evident from a cursory examination of archival photographs and plans, superimposition of ACVT models depicting the vessel in its colonial and national navy configurations reveals far more subtle hull and superstructure variations (Fig. 6.5). For example, the height and rake (the incline from the perpen- dicular towards the stern) of Protector's funnel was reduced when it became a Royal Australian Navy fleet asset. The rake of the foremast was also reduced, and an observation platform installed on the front of the foremast, while the aft mast was removed entirely. Slight alterations were also made to Protector's bridge structure, including an increase to its overall height and outboard expansion of the port and starboard wings. Even the four sets of davits that accommodated the vessel's Montagu whalers and other ship's boats were slightly altered and shifted outboard. Finally, while the increase in the height of Protector's bow is obvious in archi-
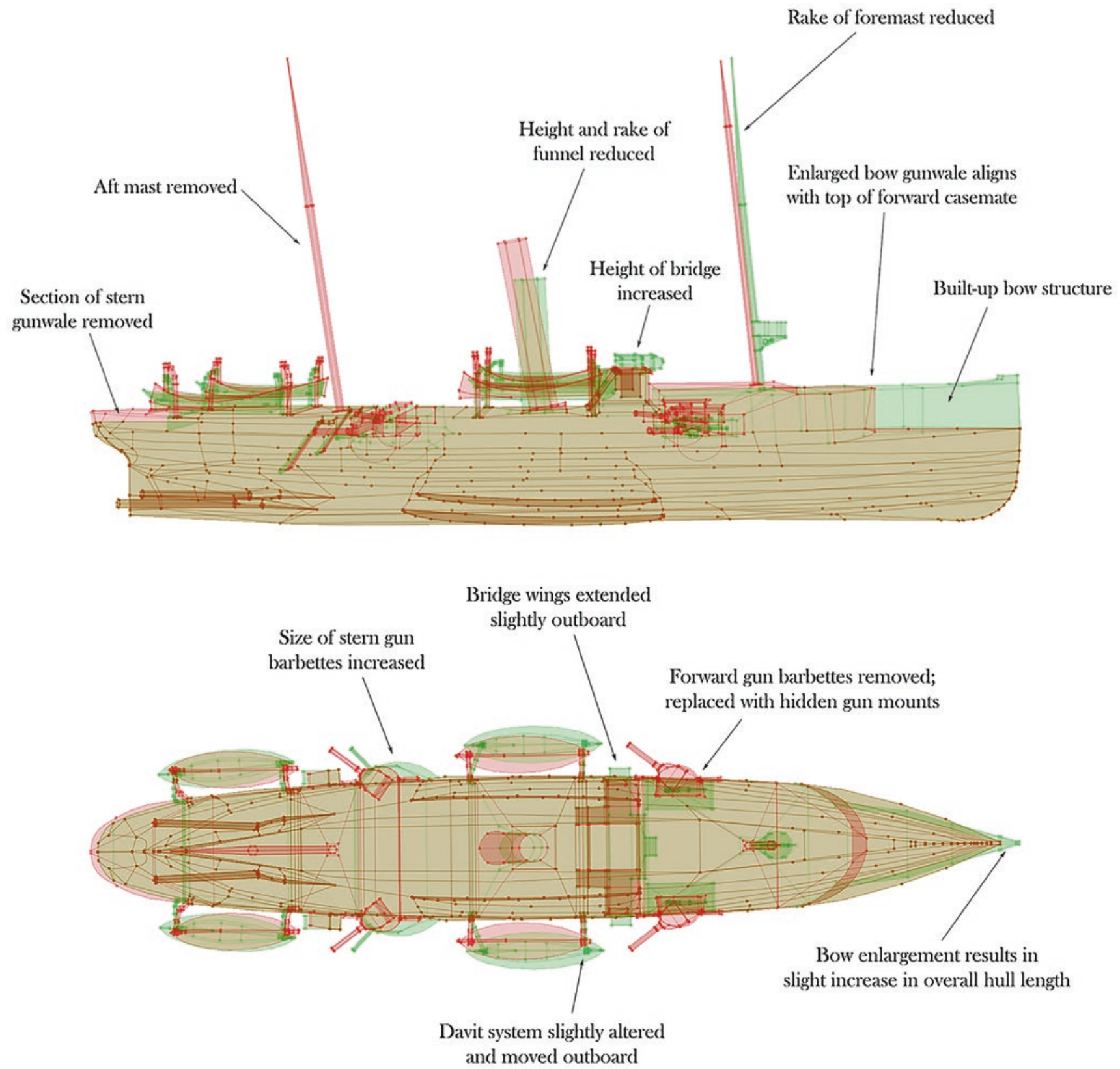

Fig. 6.5 Superimposed digital models of Protector derived from archival sources, showing the vessel in its colonial and national navy configurations (ACVT/authors) 
val sources, a barely perceptible increase in its length is also evident-but only when the superimposed models are viewed in plan (Fig. 6.5, bottom).

Alterations to Protector's armament over the course of its naval career are relatively well documented, but only in terms of the types of shipboard artillery with which it was outfitted. For example, the vessel's original complement of fixed weaponry included a bow-mounted 8-inch Armstrong rifled breech-loading gun, five 6-inch Woolwich-Armstrong rifled breech-loading guns, four 3-pounder Hotchkiss quickfiring cannon, and five 10-barrel Gatling machine guns. Following Protector's transition to the Royal Australian Navy, the Gatling guns were removed and its primary armament replaced with two 4-inch, two 12-pounder, and four 3-pounder guns (Gillett 1982, 62; Jeisman 2012, 44, 49-55, 289; Jones 1986, 62-3). Far less is known about the manner in which these weapons were mounted and deployed, and whether existing infrastructure (such as gun mountings and protective armour) was retained, adapted or removed. Some changes, such as the complete removal of Protector's forward gun barbettes (semi-circular armour plating that surrounded the vessel's rotating gun mounts) are fairly obvious in archival photographs and plans. By contrast, subtle variations to the size and form of the ship's stern barbettes are not as easy to discern but become obvious when the colonial and national navy models are superimposed over one another (see Fig. 6.5, bottom).

Superimposition of these models directly aided archaeological interpretation of surviving elements of Protector's weapons systems. Components of the vessel's forward gun mountings still remain in situ on the foredeck, including cast-steel pedestals that originally accommodated the base of each 12-pounder and served as the point on which it pivoted from side to side (Fig. 6.6, left). Because the forward gun positions were adapted from barbettes to 'disappearing' vari- ants concealed behind closed watertight hatches, a logical assumption is that their corresponding mountings were moved and modified. While the barbette was clearly removed and the pedestals may have been altered to accommodate new weaponry, comparison of the digital models reveals the mounting location itself remained unchanged (Fig. 6.6, right).

Following its removal from naval service, and subsequent conversion to the lighter Sidney, the vessel was stripped of most of its equipment and machinery. The removal of items of considerable weight, including the engines, boilers, guns, and deck machinery, caused it to rise 'up from its original water line' to such an extent that its armour belt-normally located at and slightly below the waterline-was reportedly 'well up [and] out of the water' (State Library of South Australia [SLSA], RN 100, bd 994.23 R432b). Taking the adjusted waterline of the vessel into consideration, and no doubt hoping to negate its top-heaviness and improve overall stability, Sidney's civilian owners cut the hull down so that the run of the deck was essentially level from the bow to the break of the poop. From the break, the deck rose slightly to the height of the original poop and continued aft to the end of the stern. The ship's conversion to a quasi-flush-decked configuration necessitated disassembly of the augmented bow structure, including bulwarks, decks and internal architecture back to its pre-1912 height. In addition, the superstructure amidships, including the funnel, bridge and stern bulwarks, were completely removed.

This wholesale reduction of the hull and removal of superstructure is obvious in archival photographs, and a comparison of the national navy model with that of Sidney further graphically illustrates the significant degree to which the vessel was altered in 1924 (Fig. 6.7). In addition to creating a flush deck, Sidney's civilian owners also sought to improve the run of the hull. As a warship, Protector was out-

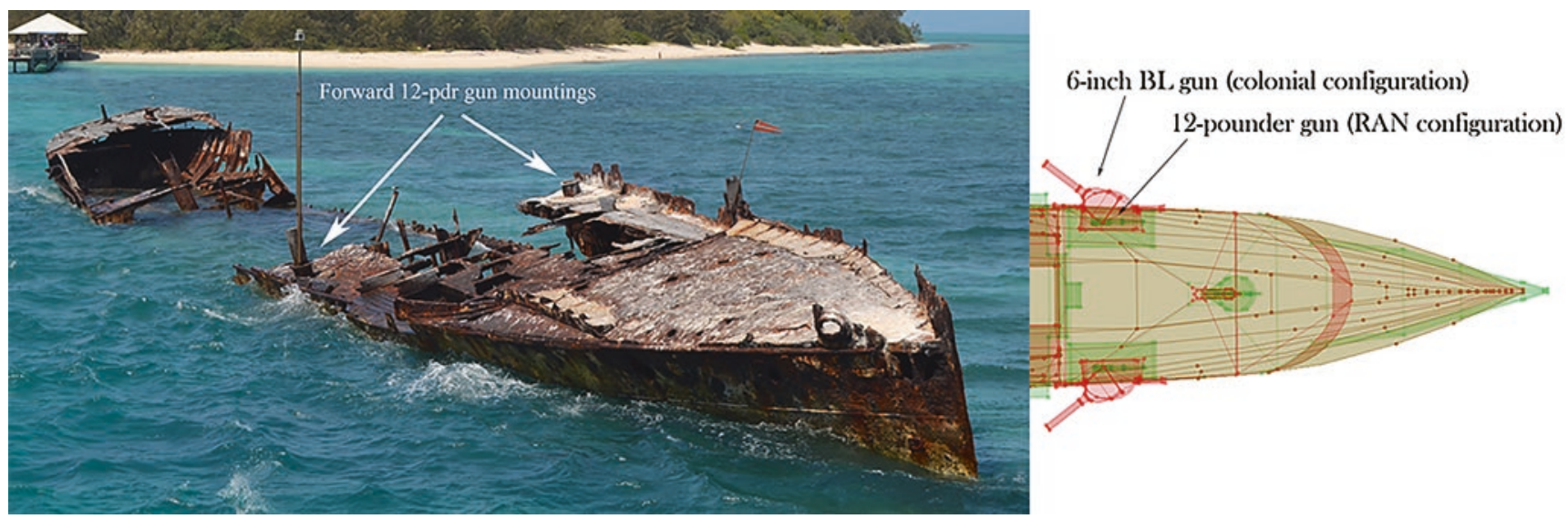

Fig. 6.6 Left: Protector's surviving hull, showing the locations of its forward 12-pounder gun mountings; right: superimposed digital models tions of the forward gun mountings were not altered. (left, James of the vessel's colonial and national navy configurations reveal the posi-

Hunter; right, ACVT) 


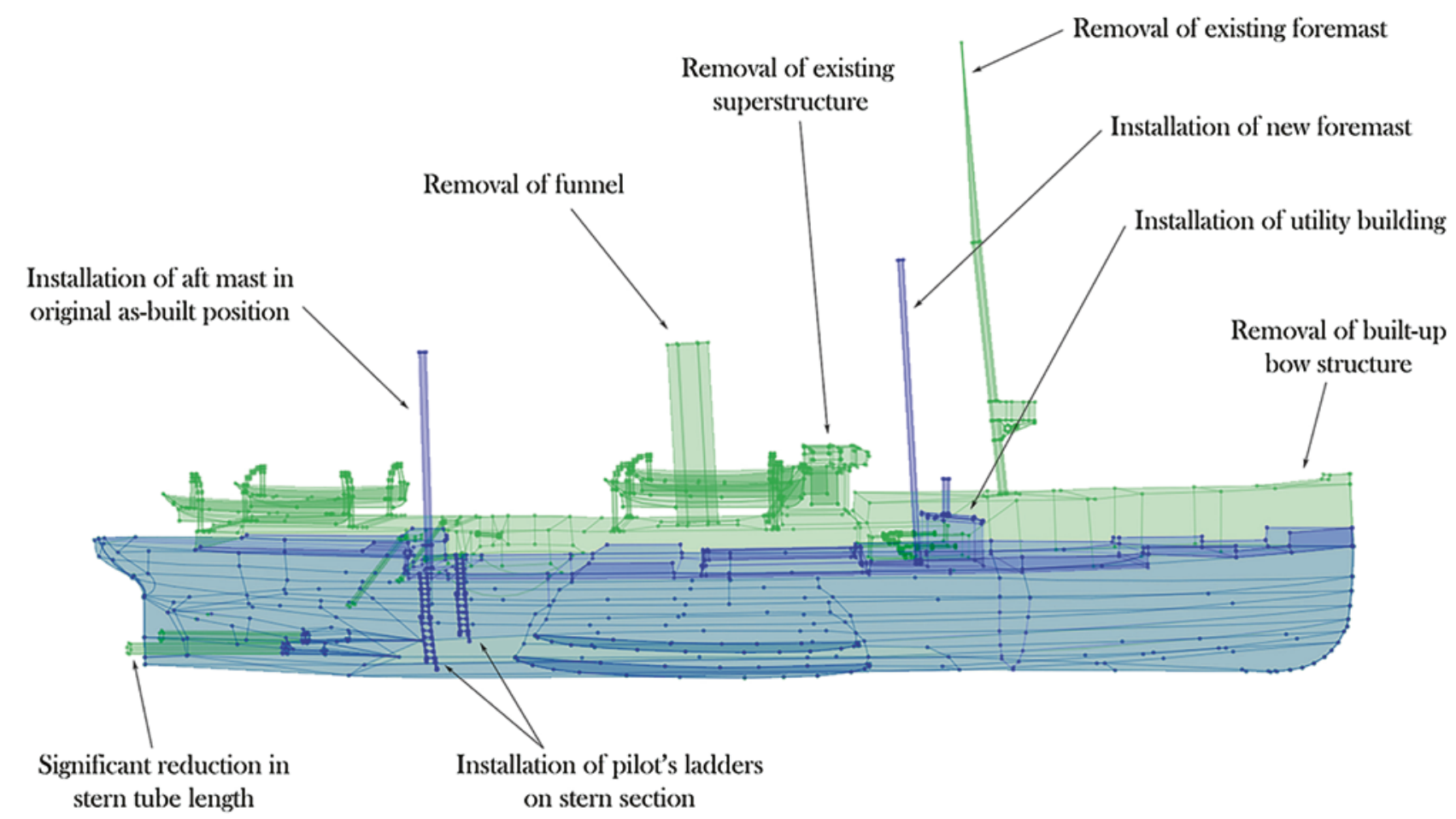

Removal of stern boarding ladder

Removal of all armament and associated enclosures (i.e., barbettes)

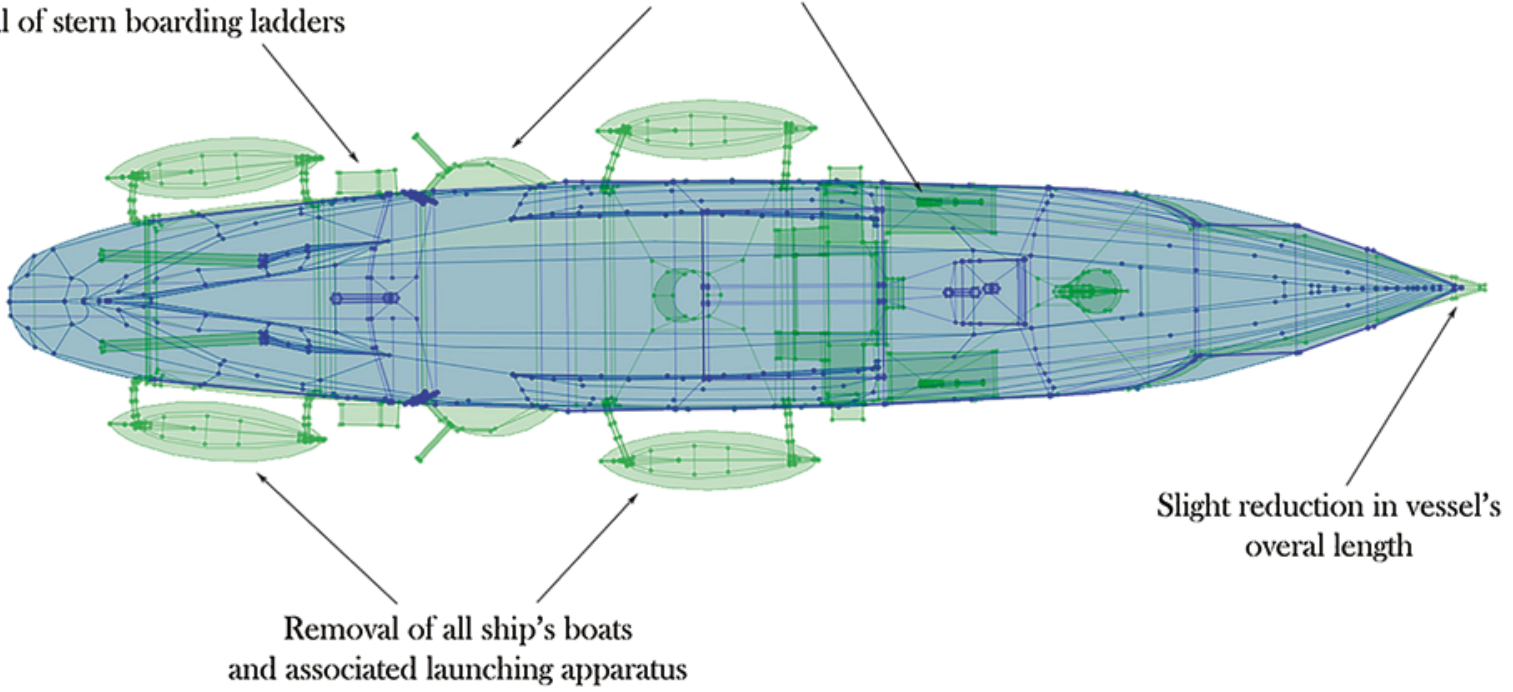

Fig. 6.7 Superimposed digital models of HMAS Protector and the lighter Sidney derived from archival sources, showing the vessel in its national navy (green) and civilian (blue) configurations (ACVT/authors)

fitted with a number of features-such as barbettes-that disrupted its otherwise clean silhouette. During its conversion to a lighter, efforts were made to modify and correct these disruptions, almost certainly as a means to improve the vessel's seaworthiness, handling qualities, or both. Such modifications included the reduction and/or removal of protruding structural elements, and the addition of steel hull plating to cover what remained and create a clean run fore and aft. When viewed in plan, the superimposed digital models show these changes very clearly as well. Also of note is the complete absence of the vessel's auxiliary boats and their launching apparatus, and reduction of the hull-via removal of bow structure—-back to its original overall length (Fig. 6.7, bottom). 
More subtle alterations to Protector that occurred during its conversion to Sidney include positioning of the vessel's masts. Protector's foremast was one of its most prominent features during its naval career but was removed when the vessel was converted to a lighter and replaced by a much shorter guyed mast that formed the basis of one of two boom derricks (simple derricks such as those aboard Sidney would have been used to move cargo into and out of the vessel's hold). Curiously, the models reveal the forward guyed mast was not stepped into the same location as the original foremast, but instead positioned slightly aft (see Fig. 6.7). This was likely done to place the derrick immediately adjacent to Sidney's forward hatch, where at least half of its cargo would have routinely been loaded and offloaded. By contrast, the aft guyed mast was stepped in the same position as the mizzenmast used aboard Protector in is original colonial navy configuration (Fig. 6.8). This appears to have been more a matter of circumstance than design, as archival photographs and archaeological investigation of the surviving hull reveal this mast was located immediately behind the section of hull transformed into Sidney's aft cargo hatch.

The superimposed models also reveal alterations to the manner in which personnel boarded and departed the vessel both prior to, and after, its conversion to a lighter. As a colonial warship, Protector was outfitted with one boarding ladder on either side of the hull immediately astern of its aft gun barbettes. This configuration remained in place following the vessel's transition to the Royal Australian Navy, with very minor adjustments to the angle and length of the ladders. When Protector was sold and converted into Sidney, the boarding ladders were removed and replaced with Jacob's ladders (see Fig. 6.7, top). Although far simpler in terms of

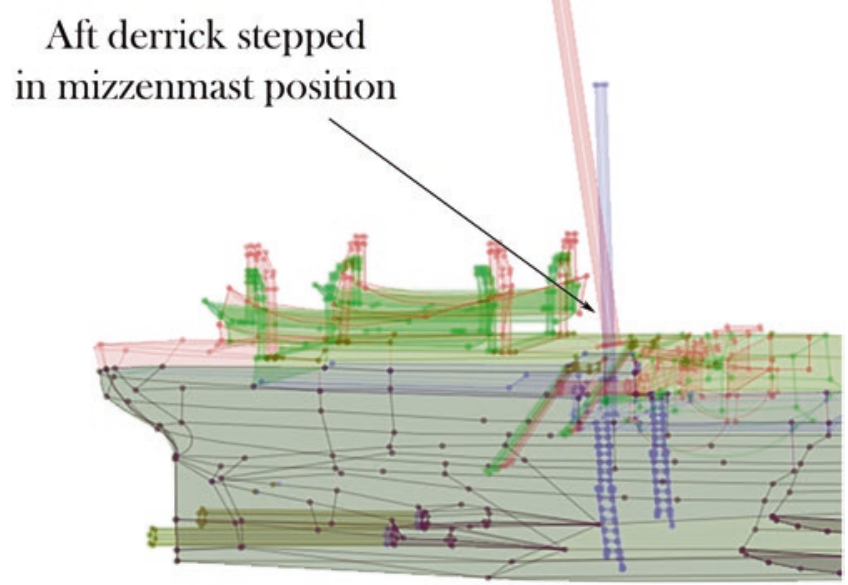

Fig. 6.8 Superimposed digital models of the stern section of Protector/Sidney derived from archival sources, showing the position of the vessel's mizzenmast and aft derrick in its respective colonial navy (red) and civilian (blue) configurations. Grey represents where all models overlap (ACVT/authors) their overall design, and easier to deploy and retract, the Jacob's ladders were positioned in approximately the same location as the boarding ladders, which suggests this section of the hull remained a preferred point of entrance and egress.

In the wake of the decision to convert Protector into a towed lighter, the vessel's propulsion system was no longer necessary and occupied valuable space that was targeted for conversion into one or more cargo storage areas. As a consequence, its engines-and their associated propellers and propeller shafts-were removed. However, the stern tubes (cylindrical iron housings through which the propeller shafts penetrated the hull to connect the propellers with the engines) were partially built into the ship's architecture and could not be completely removed without making significant alterations to Protector's lower hull. In an effort to correct the problem each stern tube was cut off at the point where it entered the hull. Additionally, the propeller shaft struts that supported the aft ends of the stern tubes were completely cut away. The removal of these unnecessary structural members would have eliminated drag, as well as a potential source of fouling.

Archaeologically, the stern tube removal process is represented by extant remnants of Protector's upper propeller shaft struts, each of which exhibits clear evidence of having been cut away at the point where it intersects the hull (see Hunter and Jateff 2016, 432, Fig. 7c). While the exact manner by which their removal was carried out is unclear, the gouges and other marks that remain on each shaft stay stump are prominent and easily discernible. Remnants of the lower propeller shaft struts, if they exist, were buried beneath the seabed and could not be examined. Removal of the majority of Protector's stern tubes may have improved the hull's hydrodynamics and handling qualities, but the structures that remained were essentially open conduits to the sea. To counteract this problem, measures were taken to close the aperture of each stern tube. This is evidenced by the presence of a circular steel plate welded just inside the port side tube that completely seals its opening (see Hunter and Jateff 2016, 432, Fig. 7d). The starboard stern tube presumably was modified in a similar fashion, but was buried beneath the seabed and could not be examined during the survey.

While the majority of archival photographs depict Protector/Sidney afloat, and effectively obscure the appearance of the hull below the waterline, a very small handful of images show the vessel completely-or almost completely_out of water. These images are significant because they provide muchneeded depictions of the vessel's hull below the waterline, which in turn have augmented the overall interpretive value of the ACVT models. They also supplied useful data that informed archaeological analysis of the stern tube removal process. Three photographs were taken in 1884 while Protector was still on the stocks at the shipyard of Sir William Armstrong \& Co. in Newcastle-on-Tyne, and two include different views of the ship's stern tubes and propellers. Three others taken in 1943 
depict Sidney aground at Facing Island in Queensland shortly after an initial ill-fated attempt by Cristian Poulson to tow it to Heron Island. Again, two photographs show the vessel's stern tubes, and clearly reveal a sizeable portion of their overall length was cut away. All of these images were integrated within the ACVT modelling dataset, and reveal approximately twothirds of each stern tube's total length was removed (see Fig. 6.7, top) - a figure that would have been difficult to discern simply by looking at the photographs themselves, or even the archaeological signatures of their removal.

\subsection{Discussion and Conclusions}

As demonstrated by the Protector case study, creation of 3D digital models from archival sources has utility in the interpretation of the 'life history' of watercraft. Further, the technique can be a useful analytical tool in the archaeological investigation of wrecked and abandoned vessels. This is especially true in instances where alterations to hull and/or superstructure are no longer evident in the archaeological record, or so subtle they are practically unrecognisable in surviving archival photographs and plans. Protector's known photographic archive covers the complete span of the vessel's life from its 1884 launch until the present day. Indeed, the ship's surviving hull continues to be documented yearly (if not monthly or weekly) by visitors to Heron Island, and the volume of images depicting it has increased exponentially with the advent of digital photography and smart phones. Many of the more significant alterations to Protector's hull and superstructure during its operational career are immediately evident in historic images, but the presence of many others-such as the variation in rake of the ship's foremast - were only identified from a comparison of digital models generated as a result of this research.

While useful, the technique also has clear limitations that may inhibit or prevent its use in certain circumstances. Perhaps one of the biggest drawbacks is the need for a large photographic archive that depicts the vessel from as many different perspectives as possible. In the case of some watercraft, the available collection of historic images is vast and varied; however, the majority of historic vessels have few, if any, existing photographs from which to derive reliable 3D models. Because it is based entirely on photographs, the technique also precludes the creation of digital models of vessels built and/or operated prior to the advent of photography. Finally, comparative models that show a vessel's change over time can only be generated if the photographic archive includes several different images that share multiple hull and/or superstructure features in common. Because they form consistent reference points, these features are absolutely necessary to the success of the SfM method. Without the right imagery, application of the technique is difficult, if not impossible.
The development of Protector 'pseudo images' from plans and schematics was the primary means by which ACVT compensated for image shortfalls, and may serve as a launching point from which to explore the feasibility of adapting the technique to other iconographic formats (such as marine paintings, sketches and engravings). The integration of other iconographic data would serve as an ideal complement to photographic material, particularly in instances where a vessel's photographic archive is limited. Similarly, it would provide a method for modelling watercraft for which no photographic archives exist, and vastly expand the temporal span of the technique's applicability.

Although it has greatly enhanced our understanding of one ship's particular history, perhaps the biggest outcome from this study is that it has expanded the potential scope and utility of iconographic data to the archaeological interpretation of historic shipwrecks and abandoned vessels generally. Archival photographs have been a mainstay in the investigation and analysis of (primarily) iron and steel vessels for some time, but have in most cases merely served to complement or verify information revealed in the archaeological record. 3D modelling of archival imagery has taken this valuable dataset a step further, and demonstrated a new means by which changes to vessels over time may be recognized, analysed and interpreted. It has also provided an opportunity for maritime archaeologists to move beyond broad qualitative statements about vessel modification and adaptation, and quantitatively interrogate how, when and in what manner specific alterations occurred. This has potentially significant ramifications for ship studies specifically, and maritime archaeology more broadly. The same technique(s) that were applied to Protector's photographic archive could be used to interpret a variety of other site types - such as elements of land-based maritime and other infrastructure-for which historic photographs exist. This can only enhance our understanding of the past, and better serve the goals of our discipline as a whole.

Acknowledgements The initiative to document, digitally model and interpret Protector would not have been possible without the assistance, advice and input of several individuals and institutions. Many thanks are due to our colleagues in the survey, research, and digital modelling teams: Daniel Pooley and John Bastian (Australian Centre for Visual Technologies), Kevin Jones, Lindl Lawton and Adam Paterson (South Australian Maritime Museum), Ian MacLeod (Western Australian Museum) and Ed Slaughter. Staff at Heron Island Research Station were excellent hosts, and must be commended for sharing information about Protector's surrounding environment and providing logistical support during the survey. Paddy Waterson (Queensland Department of Environment and Heritage) kindly provided data from previous visual inspections of Protector, and assisted with the acquisition of archaeological permits. This project was supported by an Australian Research Council Linkage Award (LP130101064), the Commonwealth of Australia's Your Community Heritage Program, and the Silentworld Foundation. 


\section{References}

Aubry M (2015) Representing 3D models for alignment and recognition. École des Ponts ParisTech, Paris

Aubry M, Russel B, Sivic J (2013) Painting-to-3D model alignment via discriminative visual elements. HAL online open-access archive (hal-00863615v1)

Baatz G, Saurer O, Köser K, Pollefys M (2012) Large scale visual geolocalization of images in mountainous terrain. In: Fitzgibbon A, Lazebnik S, Perona P, Sato Y, Schmid C (eds) Proceedings of the 12th European conference on computer vision, Florence

Baboud L, Cadik M, Eisemann E, Seidel HP (2011) Automatic phototo-terrain alignment for the annotation of mountain pictures. In Proceedings of the 2011 IEEE conference on computer vision and pattern recognition, Washington DC

Crumlin-Pedersen O (2000) To be or not to be a cog: the Bremen cog in perspective. Int J Naut Archaeol 29(1):230-246. https://doi. org/10.1006/ijna.2000.0321

Dalal N, Triggs B (2005) Histograms of oriented gradients for human detection. In: Schmid C, Soatto S, Tomasi C (eds) Proceedings of the 2005 IEEE conference on computer vision and pattern recognition, San Diego

Doersch C, Singh S, Gupta A, Sivic J, Efros AA (2012) What makes Paris look like Paris? ACM Trans Graph 31(3):101

Felzenszwalb PF, Girshick RB, McAllester D, Ramanan D (2010) Object detection with discriminatively trained part based models IEEE Trans Pattern Anal Mach Intell 32(9):1627-1645

Flatman J (2004) The iconographic evidence for maritime activities in the Middle Ages. Curr Sci 86(9):1276-1282

Flatman J (2014) Maritime iconography. In: Smith C (ed) Encyclopaedia of global archaeology. Springer, New York, pp 4666-4671

Gillett R (1982) Australia's colonial navies. Naval Historical Society of Australia, Garden Island

Hartley R, Zisserman A (2004) Multiple view geometry in computer vision. Cambridge University Press, Cambridge

Hunter J, Jateff E (2016) From battleship to breakwater: post-military adaptive reuse of the Australian warship Protector. Int J Naut Archaeol 45(2):423-440. https://doi.org/10.1111/1095-9270.12177

Hunter J, Jateff E, Herath N, van den Hengel A (2016) Protector revealed: an initiative to archaeologically document, interpret and showcase an historic Australian warship with laser scanning technology. J Cult Herit Conserv 37:25-40

Huttenlocher DP, Ullman S (1987) Object recognition using alignment. In: Proceedings of the first international conference on computer vision, London

Jeisman S (2012) Colonial gunboat: the story of HMCS Protector and the South Australian naval brigade. Adelaide

Jones C (1986) Australian colonial navies. The Australian War Memorial, Canberra

Li B, Shen C, Dai Y, van den Hengel A, He M (2015) Depth and surface normal estimation from monocular images using regression on deep features and hierarchical CRFs. In: Proceedings of the IEEE conference on computer vision and pattern recognition, pp 1119 1127. https://doi.org/10.1109/CVPR.2015.7298715

Lowe D (1987) The viewpoint consistency constraint. Int J Comput Vis 1(1):57-72

Lowe D (2004) Distinctive image features from scale-invariant keypoints. Int J Comput Vis 60(2):91-110

MacLeod I, Jateff E, Hunter J (2014) Corrosion on a wrecked colonial vessel: HMCS protector, 1882-1944. Corros Mater 39(3):50-54

McGrail S (1998) Ancient boats in Northwest Europe: the archaeology of water transport to AD 1500, Longman archaeology series. Routledge, London

National Archives of Australia, Canberra. HMAS protector: proposed arrangement of minesweeping gear, etc. MP551/1, 92/20

Nicholls B (1988) The colonial volunteers: the defence forces of the Australian colonies, 1836-1901. Allen \& Unwin, Sydney

Pennock R (2001) A warship for South Australia. Robin Pennock, Blackwood

Rapp JB (2008) A geometrical analysis of multiple viewpoint perspective in the work of Giovanni Battista Piranesi: an application of geometric restitution of perspective. J Archit 13(6):701-736. https:// doi.org/10.1080/13602360802573868

Russell BC, Sivic J, Ponce J, Dessales H (2011) Automatic alignment of paintings and photographs depicting a 3D scene. In: Proceedings of the third international IEEE workshop on 3D representation for recognition, Barcelona

Shrivastava A, Malisiewicz T, Gupta A, Efros AA (2011) Data-driven visual similarity for cross-domain image matching. In: ACM transactions on graphics/proceedings of ACM SIGGRAPH Asia 2011 30(6)

Sivic J, Zisserman A (2003) Video Google: a text retrieval approach to object matching in videos. In: Proceedings of the ninth IEEE international conference on computer vision, Nice. https://doi. org/10.1109/ICCV.2003.1238663

Snavely N, Seitz SM, Szeliski R (2006) Photo tourism: exploring photo collections in 3D. ACM Trans Graph/Proc ACM SIGGRAPH 25(3):835-846

State Library of South Australia, Adelaide. H.B. Treacy to Lt. H.M. Cooper. Research notes [RN] No. 100, bd 994.23 R432b

Steffy JR (1994) Wooden ship building and the interpretation of shipwrecks. Texas A\&M University Press, College Station

Szeliski R (2010) Computer vision: algorithms and applications. Springer, London

United States Navy (1917) Mine sweeping manual. United States Navy, Washington, DC

Villain-Gandossi C (1979) Le navire medieval à travers les miniatures des manuscrits français. In: McGrail S (ed) Archaeology of medieval ships and harbours in Northern Europe, BAR international series 66. BAR Series, Oxford, pp 195-225

Winter W, Burningham N (2001) Distinguishing different types of early 17 th-century Dutch jacht and ship through multivariate morphometric analysis of contemporary maritime art. Int J Naut Archaeol 30(1):57-73. https://doi.org/10.1016/S1057-2414(01)80007-8

Open Access This chapter is licensed under the terms of the Creative Commons Attribution 4.0 International License (http://creativecommons. org/licenses/by/4.0/), which permits use, sharing, adaptation, distribution and reproduction in any medium or format, as long as you give appropriate credit to the original author(s) and the source, provide a link to the Creative Commons licence and indicate if changes were made.

The images or other third party material in this chapter are included in the chapter's Creative Commons licence, unless indicated otherwise in a credit line to the material. If material is not included in the chapter's Creative Commons licence and your intended use is not permitted by statutory regulation or exceeds the permitted use, you will need to obtain permission directly from the copyright holder. 